\title{
O Efeito da Máscara Cirúrgica de Proteção Respiratória nos Marcadores Fisiológicos de Desempenho Aeróbio em um Corredor Recreacional
}

\section{The Effect of Respiratory Protective Surgical Mask on Physiological Markers of Endurance Performance in a Recreational Runner}

\author{
Danilo Marcelo Leite do Prado, ${ }^{1}$ V Valmir Oliveira Silvino, ${ }^{2}$ Ewerton Gomes Vieira, ${ }^{2}$ Bruno Viana Rosa, ${ }^{2}$ \\ Acácio Salvador Veras e Silva, ${ }^{2}$ Marcos Antonio Pereira dos Santos ${ }^{3}$ (] \\ Hospital das Clínicas da Faculdade de Medicina da Universidade de São Paulo, ${ }^{1}$ São Paulo, SP - Brasil \\ Universidade Federal do Piauí - Nucleo de Estudo em Fisiologia Aplicada ao Desempenho e à Saúde (NEFADS) - Departamento de Biofísica e \\ Fisiologia, ${ }^{2}$ Teresina, $\mathrm{Pl}$ - Brasil \\ Universidade Federal do Piauí, ${ }^{3}$ Teresina, PI - Brasil
}

\section{Introdução}

O advento da pandemia do Coronavírus 19 (COVID-19), que se espalhou rapidamente pelo mundo, aumentando a atenção em relação ao uso de máscara de proteção facial (MPF) não somente por profissionais da saúde, mas também pela população em geral. ${ }^{1}$ Neste contexto, o uso de MPF durante exercícios físicos em ambiente externo pode reduzir os riscos de infecção de COVID-19. Por outro lado, o uso da MPF pode aumentar a percepção subjetiva de dificuldade respiratória a partir da formação de microclimas dentro da máscara (ou seja, temperatura e umidade) e pela restrição do fluxo expiratório. ${ }^{2}$

Nos últimos anos, o número de corredores amadores aumentou significativamente entre várias populações no mundo todo, já que a corrida pode ser realizada com equipamentos mínimos e por uma ampla variedade de pessoas. ${ }^{3}$ É interessante notar que, durante o exercício aeróbio, a capacidade de adaptação do sistema cardiorrespiratório é de extrema importância, já que ele aumenta o transporte de oxigênio convectivo e difusivo, permitindo, assim, que o corpo atenda à demanda por oxigênio, entrega de substrato, e retirada do dióxido de carbono. ${ }^{4}$ Além disso, os chamados marcadores fisiológicos de desempenho aeróbio, tais como o limiar anaeróbio ventilatório, ponto de compensação respiratória, economia de corrida, e consumo máximo de oxigênio, também parecem ser importantes na definição da intensidade absoluta do exercício (ou seja, ritmo, potência). ${ }^{5}$

\section{Palavras-chave}

Coronavirus-19; Pandemia; Máscara; Dispositivo de Proteção Respiratória; Atividade Física; Desempenho Aeróbio; Educação da População; Exercício; Consumo de Oxigênio; Infecção por Coronavírus.

Correspondência: Danilo Marcelo Leite Prado •

Hospital das Clínicas da Faculdade de Medicina da Universidade de

São Paulo - Rua Dr. Enéas de Carvalho Aguiar, 44. CEP 05403-000,

São Paulo, SP - Brasil

E-mail: danilo.prado@hc.fm.usp.br

Artigo recebido em 20/07/2020, revisado em 26/11/2020, aceito em $27 / 01 / 2021$

DOI: https://doi.org/10.36660/abc.20200792
Portanto, é importante entender claramente se o uso de MPF afeta os marcadores fisiológicos do desempenho aeróbio durante a corrida. Portanto, este relato de caso avaliou o efeito do uso de MPF 1) nos marcadores fisiológicos de desempenho aeróbio e 2) na resposta cardiorrespiratória durante o exercício em um corredor recreacional.

\section{Relato de Caso}

O voluntário que participou deste relato de caso foi um corredor saudável de 28 anos, do sexo masculino, com 10 anos de experiência em meias maratonas. Nos últimos três meses, ele correu em média 35 quilômetros por semana, com uma frequência de 3-4 sessões semanais. O participante não tinha experiência com a prática de exercícios aeróbicos com o uso de MPF. O estudo foi realizado após a obtenção do termo de consentimento informado do participante. O estudo foi aprovado pelo Comitê de Ética da Universidade Federal do Piauí, Teresina, com o número de protocolo 4,429,909.

\section{Exames laboratoriais}

A investigação foi realizada em uma semana e consistiu em 2 fases. Na primeira fase, o voluntário realizou os testes de corrida usando uma MPF, e, na segunda fase, sem máscara (SM). Os testes foram realizados no mesmo período do dia, e com um intervalo de 48 horas entre si. O corredor foi submetido a 1) um teste de função pulmonar (TFP), ${ }^{6} 2$ ) um teste de esforço cardiorrespiratório (TECR) para avaliar os limiares ventilatórios e o consumo máximo de oxigênio, ${ }^{7}$ e 3) um teste de carga retangular progressivo (PSWT) para avaliar demandas cardiorrespiratórias e economia de corrida. ${ }^{8}$

A máscara do espirômetro foi colocada sobre a MFP e presa por faixas na cabeça de forma a impedir vazamentos (Figura 1). O ajuste foi verificado cuidadosamente pelos investigadores e pelo voluntário para confirmar a ausência de vazamento. $\mathrm{O}$ ajuste correto e a prevenção de vazamentos foram confirmados antes do início de cada teste.

MPF. Neste estudo, foram utilizadas máscaras cirúrgicas fabricadas em não tecido tipo II de proteção contra a COVID-19. Sua estrutura é composta por uma camada fabricada em não tecido, material filtrante (tecido meltblown), 


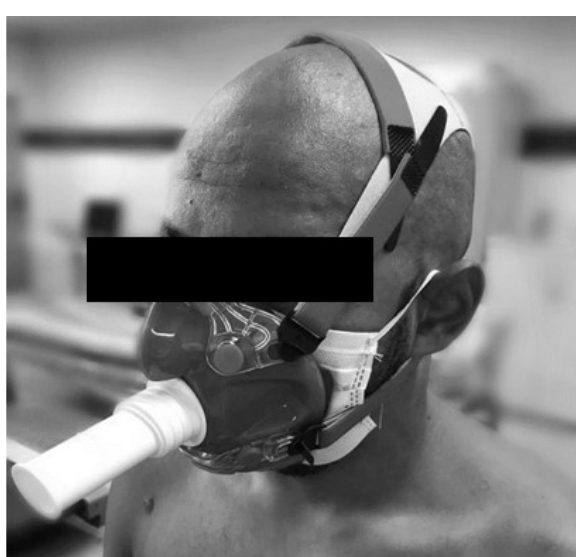

Figura 1 - Ajuste da máscara do espirômetro sobre a máscara de proteção facial.

clipe de nariz e elástico. A máscara tem formato retangular e é composta por três camadas. ${ }^{9}$

TFP. O do teste de função pulmonar foi realizado antes do TECR, de acordo com as recomendações da American Thoracic Society (Sociedade Torácica Americana). ${ }^{10}$

TECR. O teste de esforço cardiorrespiratório foi realizado em uma esteira programável (Inbramed, modelo ATL, Brasil) para determinar o consumo máximo de oxigênio ( $\mathrm{VO}_{2}$ máx), o limiar anaeróbio ventilatório (LAV) e o ponto de compensação respiratória (PCR). ${ }^{7}$ A carga de exercício (velocidade) foi aumentada a cada minuto para concluir a parte incremental do teste de esforço, que durou entre 8 e 15 minutos. A velocidade inicial do teste de esforço gradual foi de $7 \mathrm{~km} / \mathrm{h}$. As análises da troca gasosa pulmonar e das variáveis ventilatórias foram feitas continuamente, respiração a respiração, durante o TECR, utilizando um sistema de análise metabólica (Ergoestik Geratherm ${ }^{\circledR}$, Alemanha). Os seguintes critérios foram usados para definir o esforço máximo: 1) o participante demonstrou evidência subjetiva de exaustão (esforço percebido, ou seja, escala de Borg acima de 17); e 2) frequência cardíaca (FC) de pico $\geq 90 \%$ do máximo previsto para a faixa etária ou 3) quociente respiratório $(\mathrm{QR})$ no pico do exercício $\geq 1,10{ }^{11}$

PSWT. 24 horas após o TECR, o corredor foi submetido a um PSWT para avaliar a economia de corrida (EC) e a resposta cardiorrespiratória em condição de ritmo estável para três domínios de exercício: 1) $80 \%$ do LAV 2) no LAV e 3) no PCR. ${ }^{8}$ Cada domínio de intensidade durou cinco minutos. A EC foi calculada com base na avaliação do consumo de oxigênio para uma determinada distância, utilizando a equação proposta: $\mathrm{EC}\left(\mathrm{ml} \mathrm{O}_{2} \cdot \mathrm{kg}^{-1} \cdot \mathrm{km}^{-1}\right)=\mathrm{VO}_{2}$ $\left(\mathrm{ml} \cdot \mathrm{kg}^{-1} \cdot \mathrm{h}^{-1}\right)$ x $60 /$ velocidade $\left(\mathrm{Km} . \mathrm{h}^{-1}\right)$. $^{12}$ Para a avaliação da percepção subjetiva de esforço (PSE) foi utilizada a escala de Borg de 15 pontos (6 a 20), tanto no TCER quanto no PSWT. ${ }^{13}$

\section{Resultados}

TFP. O corredor apresentou valores similares para os volumes pulmonares e resistência ao fluxo expiratório
(Tabela 1) nas condições com MPF e SM. Entretanto, o corredor recreacional apresentou valores reduzidos de taxa de pico de fluxo expiratório (PFE) ao usar a MPF em comparação à situação $\mathrm{SM}(\triangle \%=-25,0$; Tabela 1$)$.

TECR. Para ambas as condições, os dados deste estudo apresentaram valores semelhantes de $\mathrm{VO}_{2}$ máx, $\mathrm{FC}$ de pico, e pulso de $\mathrm{O}_{2}$. Entretanto, o corredor recreacional apresentou $\mathrm{VVO}_{2}$ máx, ventilação pulmonar (VE), e frequência respiratória (FR) menores enquanto utilizava a MPF $(\triangle \%=-10,5,-17,6$ e -24.0 , respectivamente; Tabela 1 ). Por outro lado, os resultados deste estudo apontaram valores de volume corrente (VC) mais altos com o uso da máscara ( $\Delta \%=10,0$, Tabela 1$)$.

Em relação aos limiares ventilatórios, o voluntário apresentou valores de velocidade similares para ambas as condições. Entretanto, nossos achados apresentaram diferenças no $\mathrm{VO}_{2}$ (mL.kg1. $\min ^{1}$ e L.min ${ }^{1}$ ) e na FC (Tabela 1$)$.

A resposta cardiorrespiratória durante o TECR está descrita na Figura 2. Em relação ao $\mathrm{VE} / \mathrm{VO}_{2^{\prime}}$ o corredor apresentou valores menores enquanto usava a MPF, em comparação à situação SM (Figura 2A). Da mesma forma, foi observada uma redução na razão FR/VC (Figura 2B). Em contrapartida, o voluntário demonstrou uma resposta de FC mais alta enquanto usava a MPF, em comparação à situação SM (Figura 2C). Além disso, observou-se uma resposta semelhante de pulso de $\mathrm{O}_{2}$ para ambas as condições (Figura 2D).

PSWT. O corredor recreacional apresentou valores mais altos de EC, $\mathrm{VO}_{2}$ e FC enquanto usava a MPF (Figuras 3A, B e $\mathrm{D}$, respectivamente). Por outro lado, o voluntário demonstrou valores de VE menores enquanto usava a MPF, em comparação à situação SM (Figura 3C).

PSE. Os resultados deste estudo demonstraram que a PSE durante o TECR foi mais alta com o uso da MPF, quando comparado à condição controle $(\Delta=1$ ponto; nas velocidades $=9,10,13,14,15,16$, e 17 km/h; Figura 4A). Da mesma forma, durante o PSWT, o participante apresentou níveis elevados de PSE enquanto usava a MPF no $\operatorname{LAV}(\Delta=2$ pontos) e no $\operatorname{PCR}(\triangle=2$ pontos).

\section{Discussão}

Os dados deste estudo sugerem que o uso de máscara de proteção facial afetou a tolerância ao exercício e economia de corrida em um corredor recreacional. Consta na literatura que capacidade cardiopulmonar de exercício e sensação de conforto são reduzidos pelo uso de máscaras cirúrgicas, e são significativamente reduzidos com o uso de máscaras faciais FFP2/N95 em sujeitos saudáveis. ${ }^{14}$ Além disso, observou-se que o uso de máscara cirúrgica não afeta a capacidade de função cardiopulmonar durante exercícios que envolvem pedalada. ${ }^{15}$ Entretanto, até onde se sabe, este é o primeiro relato de caso que avaliou especificamente o efeito de uma máscara de proteção facial nos marcadores fisiológicos de desempenho aeróbio em um corredor recreacional.

É interessante notar que uma corrida de intensidade auto selecionável depende dos marcadores psicofisiológicos de desempenho aeróbio. ${ }^{5,16}$ Os resultados do presente estudo apresentaram uma resposta similar em relação ao $\mathrm{VO}_{2}$ máx 


\section{Relato de Caso}

\section{Tabela 1 - Parâmetros físicos e cardiorrespiratórios}

\begin{tabular}{|c|c|c|c|}
\hline \multicolumn{4}{|l|}{ Medidas físicas } \\
\hline Idade (anos) & 28,0 & & \\
\hline Peso (kg) & 81,0 & & \\
\hline Altura $(\mathrm{cm})$ & 175,0 & & \\
\hline Teste de função pulmonar & MPF & SM & $\Delta \%$ \\
\hline CVF (L) & 4,3 & 4,4 & 0,0 \\
\hline $\operatorname{VEF}_{1}(L)$ & 4,0 & 4,1 & 0,0 \\
\hline $\mathrm{VEF}_{1} / \mathrm{CVF}(\%)$ & 92,3 & 92,3 & 0,0 \\
\hline PFE (L/s) & 6,9 & 9,2 & 25,0 \\
\hline \multicolumn{4}{|c|}{ Teste de esforço cardiorrespiratório } \\
\hline $\mathrm{VO}_{2} \max \left(\mathrm{mL} \cdot \mathrm{kg}^{1} \cdot \mathrm{min}^{1}\right)$ & 45,5 & 45,6 & 0,0 \\
\hline $\mathrm{VO}_{2} \max \left(\mathrm{L} \cdot \mathrm{min}^{1}\right)$ & 3,69 & 3,71 & 0,0 \\
\hline $\mathrm{VVO}_{2} \max (\mathrm{km} / \mathrm{h})$ & 17,0 & 19,0 & 10,5 \\
\hline Pico de QR (unidades) & 1,21 & 1,18 & 0,02 \\
\hline FC de pico (bpm) & 184 & 185 & 0,0 \\
\hline Pico de pulso de $\mathrm{O}_{2}(\mathrm{ml} / \mathrm{bpm})$ & 20,3 & 20,1 & 0,0 \\
\hline VE $\max \left(\right.$ L.min $\left.{ }^{1}\right)$ & 116,2 & 141,1 & 17,6 \\
\hline $\mathrm{FR}\left(\mathrm{b} \cdot \mathrm{min}^{1}\right)$ & 57 & 75 & 24,0 \\
\hline VC $\left(\right.$ L.min $\left.{ }^{1}\right)$ & 2,1 & 1,9 & 10,0 \\
\hline \multicolumn{4}{|l|}{ Limiar anaeróbio ventilatório } \\
\hline $\mathrm{VO}_{2}\left(\mathrm{~mL} \cdot \mathrm{kg}^{1} \cdot \mathrm{min}^{1}\right)$ & 30,5 & 28,5 & 0,07 \\
\hline $\mathrm{VO}_{2}\left(\right.$ L.min $\left.{ }^{1}\right)$ & 2,45 & 2,31 & 0,06 \\
\hline Velocidade $(\mathrm{km} / \mathrm{h})$ & 11,0 & 11,0 & 0,0 \\
\hline $\mathrm{FC}(\mathrm{bpm})$ & 163 & 154 & 0,06 \\
\hline \multicolumn{4}{|c|}{ Ponto de compensação respiratória } \\
\hline $\mathrm{VO}_{2}\left(\mathrm{~mL} \cdot \mathrm{kg}^{1} \cdot \mathrm{min}^{1}\right)$ & 34,9 & 32,7 & 0,06 \\
\hline $\mathrm{VO}_{2}\left(\right.$ L.min $\left.{ }^{1}\right)$ & 2,82 & 2,65 & 0,06 \\
\hline Velocidade $(\mathrm{km} / \mathrm{h})$ & 13,0 & 13,0 & 0,0 \\
\hline $\mathrm{FC}(\mathrm{bpm})$ & 174 & 165 & 0,05 \\
\hline
\end{tabular}

Simbolos e abreviaturas: MPF: máscara de proteção facial; SM: sem máscara ; CVF: capacidade vital funcional; VEF ; volume expiratório forçado em 1 segundo; VEF /CVF: relação volume expiratório forçado em 1 segundo e capacidade vital funcional; PFE: pico de fluxo expiratório; VO max: consumo máximo de oxigênio; WVO max: velocidade de captação máxima de oxigênio; QR: quociente respiratório; FC: frequência cardiaca; VE: ventilação pulmonar; FR: frequência respiratória; VC: volume corrente; L: litros; L/s: litros por segundos; km/h: quilômetros por hora; bpm: batimentos por minuto.

e aos limiares ventilatórios com o uso de máscara. Por outro lado, o corredor recreacional apresentou menor velocidade na intensidade do $\mathrm{VO}_{2}$ max com o uso da MPF. É importante notar que os achados deste estudo sugerem que, embora a capacidade de transporte e utilização de oxigênio tivesse sido preservada, o corredor apresentou menor tolerância ao exercício. Vale ressaltar que o participante também apresentou redução da EC com o uso da MPF, o que sugere maiores demandas de oxigênio durante a corrida em comparação com a condição SM.

Outro ponto interessante é como a resposta ventilatória se adapta ao uso da MPF durante o TECR e o PSWT. Durante o exercício físico, há um aumento da taxa metabólica e, consequentemente, em demandas ventilatórias. Vale notar também que o corredor demonstrou resposta ventilatória menor durante o exercício com o uso da MPF. Especificamente, os resultados deste estudo apresentaram valores menores da razão $\mathrm{VE} / \mathrm{VO}_{2}$, sugerindo maior eficiência ventilatória com o uso de MPF. Entretanto, apesar da melhoria da eficiência ventilatória, o voluntário apresentou maior desconforto respiratório com o uso da MPF.

Com base nos achados mencionados acima, surge a seguinte pergunta: quais são os mecanismos fisiológicos subjacentes ao desconforto respiratório com o uso da MPF? De fato, sugere-se que fatores associados ao aumento da obstrução do fluxo expiratório podem estar relacionados. Neste contexto, os resultados deste estudo apresentaram níveis menores de TPFE e VE no pico do exercício. 

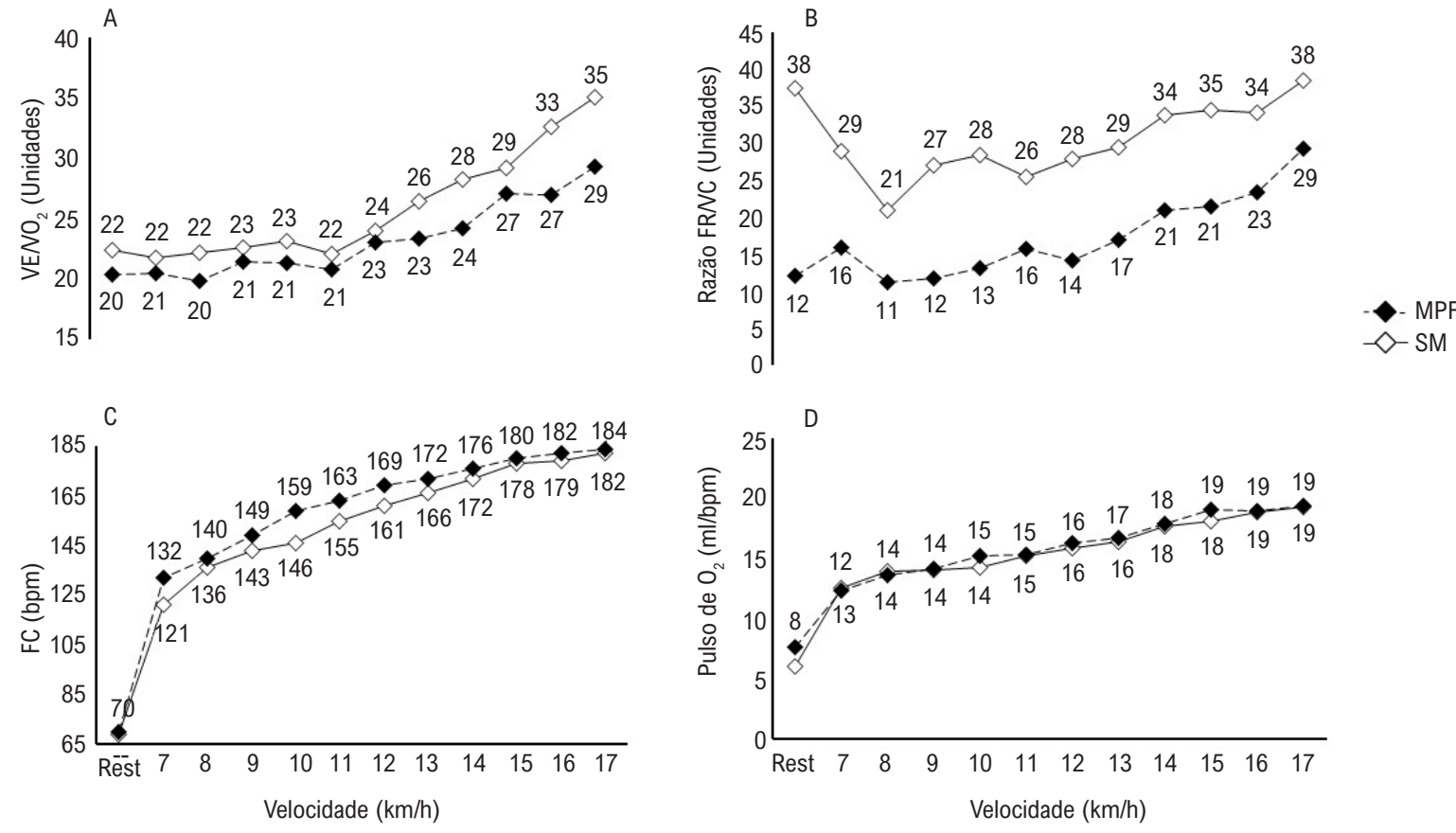

Figura 2 - Resposta cardiorrespiratória durante o TECR em um corredor recreacional com e sem o uso de MPF. Painel A=VENO ; Painel B= razão FRNC; Painel $C=F C$; Painel $D=$ pulso de $O_{2}$. MPF: máscara de proteção facial; SM: sem máscara; TECR: teste de esforço cardiorrespiratório; VENO $0_{2}$ : equivalente ventilatório para oxigênio; razão FRNC: razão da frequência respiratória e volume corrente; FC: frequência cardíaca.

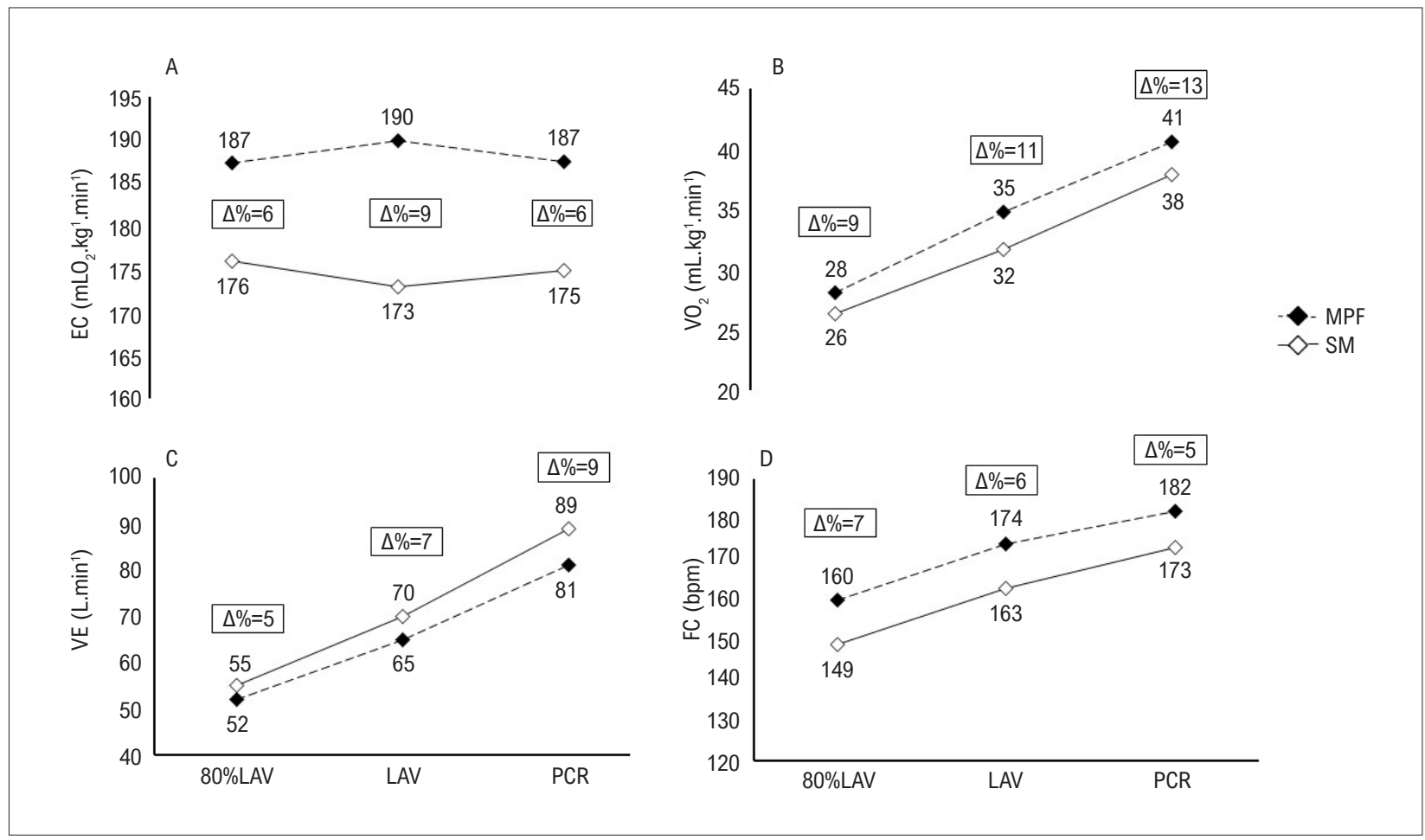

Figura 3 - Resposta cardiorrespiratória durante o PSWT em um corredor recreacional com e sem o uso de MPF. Painel $A=E C$; Painel $B=V O$; Painel $C=V E$; Painel D= FC. MPF: máscara de proteção facial; SM: sem máscara; PSWT: teste de carga retangular progressivo; EC: economia de corrida; VE: ventilação pulmonar; FC: frequência cardiaca; LAV: limiar anaeróbio ventilatório; PCR: ponto de compensação respiratório. 


\section{Relato de Caso}

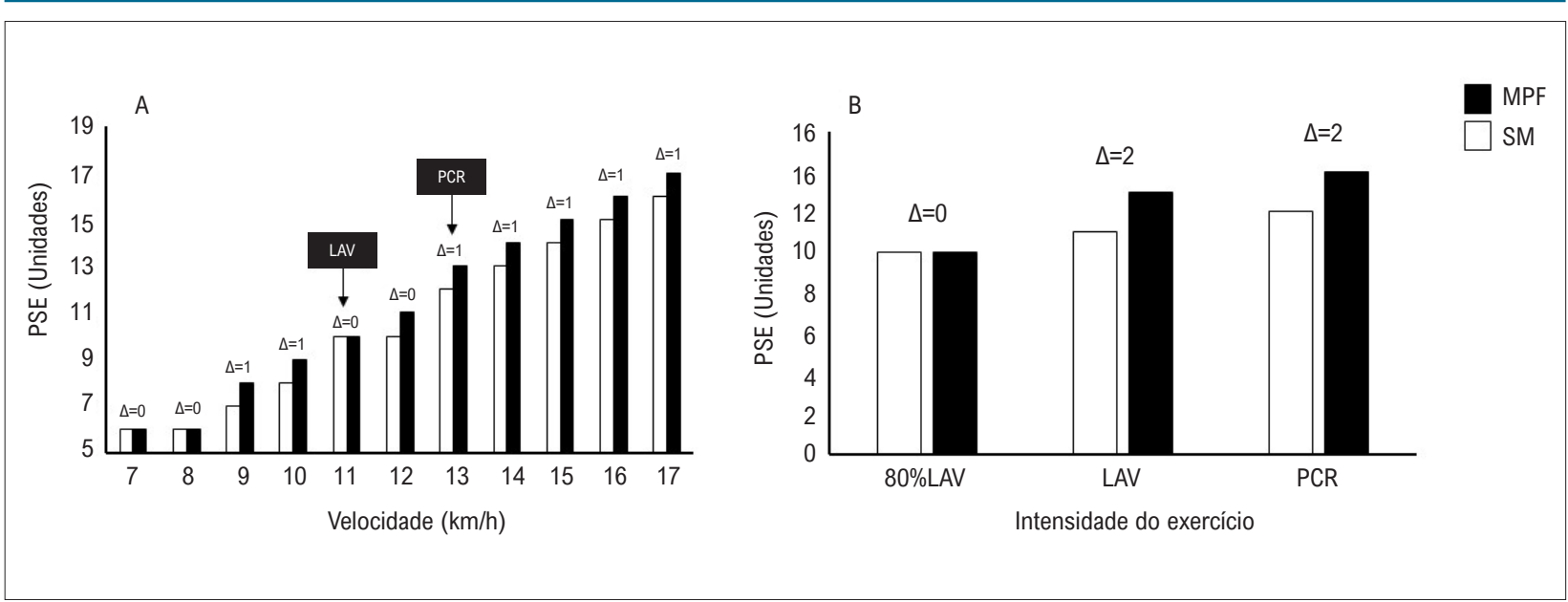

Figura 4 - Classificação da percepção subjetiva do esforço durante o TECR (painel A) e PSWT (painel B) em um corredor recreacional com e sem o uso de MPF. MPF: máscara de proteção facial; SM: sem máscaras; TECR: teste de esforço cardiorrespiratório; PSWT: teste de carga retangular progressivo; PSE: percepção subjetiva de esforço; LAV: limiar anaeróbio ventilatório; PCR: ponto de compensação respiratória.

Além disso, em relação ao padrão respiratório, o corredor apresentou uma razão FR/VC reduzida com o uso da MPF. É importante observar que a razão FR/VC é utilizada para avaliar indiretamente as interações mecânicas/ventilatórias durante o exercício. ${ }^{17}$ Neste sentido, para um determinado resultado ventilatório, o corredor aumentou o volume corrente de forma mais aguda que a frequência respiratória, aumentando consequentemente o esforço da musculatora inspiratória e, portanto, a sensação de esforço respiratório.

Por último, os dados deste estudo sugerem uma associação entre os esforços da musculatura inspiratória e um aumento das demandas de oxigênio e da resposta de frequência cardíaca durante o exercício com o uso de MPF. Neste contexto, Harms et al. ${ }^{18}$ demonstraram que a descarga da musculatura inspiratória durante o exercício aeróbico está associada com redução do $\mathrm{VO}_{2}$ e nível de dispnéia. Por exemplo, há evidências de que um esforço inspiratório maior durante o exercício está relacionado ao aumento da ativação do metaborreflexo do músculo inspiratório e, portanto, do fluxo simpático. ${ }^{19}$ É interessante notar que, no mesmo estudo, ${ }^{19}$ os autores observaram que cinco semanas de treinamento da musculatura inspiratória foram suficientes para aumentar a sua resistência e atenuar o aumento da frequência cardíaca durante o exercício.

\section{Aplicações práticas}

O presente relato de caso indica que a tolerância ao exercício e a economia de corrida foram reduzidas quando o corredor recreacional usou uma máscara de proteção facial. Além disso, os achados deste estudo sugerem uma possível associação entre aumento da obstrução do fluxo expiratório, maior sobrecarga mecânica na musculatura inspiratória demandas cardiovasculares mais altas durante o exercício aeróbio. É importante destacar que cada teste durou menos de 20 minutos, o que ajudou a manter a condição e o funcionamento da máscara.
Portanto, com base nos achados do presente relato de caso, sugere-se que as seguintes estratégias sejam usadas para minimizar o desconforto respiratório durante o exercício aeróbio com o uso de MPF: 1) inclusão do treinamento da musculatura inspiratória no programa de treinamento aeróbio; 2) prescrição da intensidade do exercício aeróbio com base na frequência cardíaca de reserva (FCR) (ou seja, método Karvonen) ou limiares ventilatórios (ou seja, LAV e PCR); 3) prescrição da intensidade de exercícios aeróbios em três zonas, ou seja Zona 1 - fácil (<LAV), Zona 2 - moderada (entre LAV e PCR); e Zona 3 - alto impacto (>PCR); e 4) para indivíduos sedentários e pacientes com doenças crônicas, sugere-se que, nos estágios iniciais do programa de treinamento aeróbio, o exercício seja de baixa intensidade (ou seja, < LAV ou 30-40\% da RFC).

\section{Conclusões}

Os resultados deste estudo sugerem que o corredor recreacional, ao usar a MPF, apresentou: 1) diminuição da resistência ao exercício apesar da resposta semelhante no $\mathrm{VO}_{2}$ máx e limiares ventilatórios; 2) diminuição economia de corrida; 3) um aumento na demanda cardiovascular em relação à resposta da frequência cardíaca; 4) aumento da carga sobre os músculos respiratórios com o padrão respiratório adotado durante o exercício, apesar da menor demanda ventilatória; e 5) um aumento na classificação da percepção subjetiva do esforço e no desconforto respiratório.

\section{Agradecimentos}

Os autores são gratos ao voluntário por seu envolvimento no estudo.

\section{Contribuições dos autores}

Concepção e desenho da pesquisa: Prado DML, Santos MAP. Análises e interpretação dos dados: Prado DML; 
Obtenção dos dados: Silvino VO, Vieira EG, Rosa BV, Santos MAP; Análise estatística: Prado DML, Silvino VO. Redação do manuscrito: Prado DML, Silvino VO, Santos MAP, Silva ASV; Revisão crítica do manuscrito quanto ao conteúdo intelectual importante: Prado DML, Silva ASV, Santos MAP.

\section{Potencial conflito de interesse}

Não há potencial conflito de interesse com este artigo.

\section{Fontes de financiamento}

O presente estudo não teve fontes de financiamento externas.

\section{Referências}

1. Chu DK, Akl EA, Duda S, Solo K, Yaacoub S, Schünemann HJ, et al. Physical distancing, face masks, and eye protection to prevent person-to-person transmission of SARS-CoV-2 and COVID-19: a systematic review and metaanalysis. Lancet.2020;6736(10242):1973-87.

2. LiY, Tokura H, Guo YP, Wong ASW, Wong T, Chung J, et al. Effects of wearing N95 and surgical facemasks on heart rate, thermal stress and subjective sensations. Int Arch Occup Environ Health. 2005;78(6):501-9.

3. Videbæk S, Bueno AM, Nielsen RO, Rasmussen S. Incidence of RunningRelated Injuries Per 1000 h of running in Different Types of Runners: A Systematic Review and Meta-Analysis. Sport Med. 2015;45(7):1017-26.

4. Richardson RS. Oxygen transport and utilization: An integration of the muscle systems. Am J Physiol - Adv Physiol Educ. 2003;27(1-4):183-91.

5. Joyner MJ, Coyle EF. Endurance exercise performance: the physiology of champions. J Physiol. 2008;586(1):35-44.

6. Ponce MC, Sharma S. Pulmonary function tests. In: Stat Pearls [Internet] [Internet]. Treasure Island: StatPearls Publishing; 2020. p. 653-64.[Cited in 2020 Feb 21]. Available from: https://www.ncbi.nlm.nih.gov/books/ NBK482339/?report $=$ classic

7. Herdy AH, Ritt LEF, Stein R, de Araújo CGS, Milani M, Meneghelo RS, et al. Cardiopulmonary exercise test: Background, applicability and interpretation. Arq Bras Cardiol. 2016;107(5):467-81.

8. Barner KR, Kilding AE. Running economy: measurement, norms, and determing factors. Sports Medicine. 2015;1:8

9. World Health Organization. Advice on the use of masks in the context of COVID-19. Interim Guid [Internet]. 2020;1-5.[Cited in 2020 Dec 12]. Available from: https://www.who.int/docs/default-

10. Graham BL, Steenbruggen I, Barjaktarevic IZ, Cooper BG, Hall GL, Hallstrand TS, et al. Standardization of spirometry 2019 update an official

\section{Vinculação acadêmica}

Este estudo não está associado com nenhuma tese ou dissertação de pós-graduação.

\section{Aprovação ética e consentimento aprovado}

Este estudo foi aprovado pelo Comitê de Ética de Pesquisa da Universidade Federal do Piauí, Teresina, Brasil, com o protocolo número 4,429,909. Todos os procedimentos neste estudo foram efetuados de acordo com a declaração de Helsinki de 1975, atualizada em 2013. O consentimento informado foi obtido do participante incluso neste estudo.
American Thoracic Society and European Respiratory Society technical statement. Am J Respir Crit Care Med. 2019;200(8):E70-88.

11. Howley ET, Bassett DR, Welch HG. Criteria for maximal oxygen uptake: review and commentary. Med Sci Sport Exerc. 1995;27(9):1292-301.

12. di Prampero PE. Energy Cost of Human Locomotion on Land and in Water Int J Sports Med. 1986;7(2):55-72.

13. Borg GA. Psychophysical bases of perceived exertion. Med Sci Sport Exerc. 1982;14(5):377-81.

14. Fikenzer S, Lavall TUD, Falz URR, Hepp MBP. Effects of surgical and FFP2/N95 face masks on cardiopulmonary exercise capacity. Clin Res Cardiol [Internet]. 2020;1-9. Available from: https://doi.org/10.1007/ s00392-020-01704-y

15. Otsuka A, Komagata J, Sakamoto Y. Wearing a surgical mask does not affect the anaerobic threshold during pedaling exercise. J Hum Sport Exerc. $2020 ; 17(1): 1-7$.

16. Scherr J, Wolfarth B, Christle JW, Pressler A, Wagenpfeil S, Halle M. Associations between Borg's rating of perceived exertion and physiological measures of exercise intensity. Eur J Appl Physiol. $2013 ; 113(1): 147-55$.

17. Neder JA, Dal Corso S, Malaguti C, Reis S, De Fuccio MB, Schmidt H, et al. The pattern and timing of breathing during incremental exercise: $\mathrm{A}$ normative study. Eur Respir J. 2003;21(3):530-8.

18. Harms CA, Wetter TJ, St Croix CM, Pegelow DF, Dempsey JA. Effects of respiratory muscle work on exercise performance. J Appl Physiol. 2000; jul; 89(1):131-8.

19. WittJD, Guenette JA, Rupert JL, Mckenzie DC, Sheel AW. Inspiratory muscle training attenuates the human respiratory muscle metaboreflex. J Physiol. 2007; 584(3):1019-28. 